\title{
Accuracy and Wear Evaluation of the Customized Zirconia Guided Sleeves
}

\author{
Yu-Feng Chen ${ }^{1,2}{ }^{\mathbb{D}}$, Chin-Yun Pan ${ }^{3,4,5} \mathbb{D}$, Yung-Chung Chen ${ }^{2,6}$, Je-Kang Du 5,7 (D) and Ting-Hsun Lan ${ }^{5,7, *(\mathbb{D})}$ \\ 1 Division of Oral and Maxillofacial Surgery, Department of Dentistry, Kaohsiung Medical University Hospital, \\ Kaohsiung 807378, Taiwan; omsyfchen@gmail.com \\ 2 School of Dentistry, Institute of Oral Medicine, College of Medicine, National Cheng Kung University, Tainan \\ 701401, Taiwan; yc_chen@mail.ncku.edu.tw \\ 3 Department of Dentistry, Kaohsiung Municipal Siaogang Hospital, Kaohsiung 812022, Taiwan; \\ spig.pan6363@gmail.com \\ 4 Division of Orthodontics, Department of Dentistry, Kaohsiung Medical University Hospital, \\ Kaohsiung 807378, Taiwan \\ 5 School of Dentistry, College of Dental Medicine, Kaohsiung Medical University, Kaohsiung 807377, Taiwan; \\ dujekang@gmail.com \\ 6 Division of Prosthodontics, Department of Stomatology, National Cheng Kung University Hospital, \\ College of Medicine, National Cheng Kung University, Tainan 701401, Taiwan \\ 7 Division of Prosthodontics, Department of Dentistry, Kaohsiung Medical University Hospital, \\ Kaohsiung 807378, Taiwan \\ * Correspondence: tinghsun.lan@gmail.com; Tel.: +886-7-3121101 (ext. 2154-11)
}

Citation: Chen, Y.-F.; Pan, C.-Y.; Chen, Y.-C.; Du, J.-K.; Lan, T.-H. Accuracy and Wear Evaluation of the Customized Zirconia Guided Sleeves. Appl. Sci. 2021, 11, 9035. https:// doi.org/10.3390/app11199035

Academic Editor: Joseph Nissan

Received: 3 September 2021

Accepted: 26 September 2021

Published: 28 September 2021

Publisher's Note: MDPI stays neutral with regard to jurisdictional claims in published maps and institutional affiliations.

Copyright: (c) 2021 by the authors. Licensee MDPI, Basel, Switzerland. This article is an open access article distributed under the terms and conditions of the Creative Commons Attribution (CC BY) license (https:// creativecommons.org/licenses/by/ $4.0 /)$.
Abstract: This in vitro study investigated the accuracy and wear conditions of three drill sleeve distances $(0.01,0.02$, and $0.03 \mathrm{~mm})$ for 3D-guided stents in simulated clinical dental implant surgery. Fifteen sets of upper and lower partially edentulous epoxy tooling board models with four edentulous first molar sites were prepared in a Nissin Simple Manikin II and set on a dental chair. Sixty computeraided design and computer-aided manufacturing (CAD/CAM) designed and guided stents with three drill sleeve distances were prepared in this study. The maximum height (Sz) of the wear roughness of drills, maximum deviation, and drilling time were observed. The highest maximum horizontal deviations were observed at the upper first molar $(0.48 \pm 0.12 \mathrm{~mm}, p<0.001)$. The highest maximum vertical and angular deviations were observed at the lower left first molar $(1.08 \pm 0.35 \mathrm{~mm}$ and $5.61^{\circ} \pm 1.21^{\circ}$, respectively, $\left.p<0.001\right)$. Only angular deviation significantly differed among the three drill sleeve distances $(p=0.046)$; the $0.03 \mathrm{~mm}$ distance exhibited the maximum angular deviation $\left(3.92^{\circ} \pm 1.87^{\circ}\right)$. The bigger drill sleeve distance $(0.03 \mathrm{~mm})$ was associated with more wear roughness $(8.70 \pm 2.29 \mu \mathrm{m})$ of the drills. Guided stents with varying drill-sleeve distances $(0.01$, 0.02 , and $0.03 \mathrm{~mm}$ ) exhibited no significant difference in preparation drilling time and abrasive wear. In practice, the optimal drill sleeve distance for single-type CAD/CAM-guided stents of dental implantation was $0.01 \mathrm{~mm}$.

Keywords: drill sleeve distance; dental implant; CAD/CAM; guided stent

\section{Introduction}

Modern advancements in implant dentistry have revolutionized computer-assisted digital workflows [1]. Computer-guided implant surgery has been demonstrated to be more precise and accurate than conventional surgical guides or free-hand implant placement [2-8]. Cone-beam computed tomography $(\mathrm{CBCT})$ produces 3-dimensional (3D) images that can be stored as digital imaging and communications in medicine (DICOM) files, and intraoral scan and conventional models can generate images as stereolithography (STL) files. Software can merge DICOM and STL files, virtual planning software can be used to determine the ideal implant position for the surgical guided stent. These guides are produced using CAD/CAM technology (e.g., stereolithography models) or manually produced in a dental laboratory using computer-aided implantology (CAI) [9-11]. 
Tang et al. [7] demonstrated that an implant deviation of $1.22 \pm 0.63 \mathrm{~mm}$ at the entrance point and $1.91 \pm 1.17 \mathrm{~mm}$ at the apical point and an angulation of $7.93^{\circ} \pm 5.56^{\circ}$ were achieved through free-hand placement. The application of a CAI surgical template during surgery could enhance the accuracy of implant placement. Yeung et al. [12] examined implant installation by using 3D-printed guides and reported a deviation of $0.02 \pm 0.13 \mathrm{~mm}$ mesially and $0.07 \pm 0.14 \mathrm{~mm}$ distally and a mesiodistal angulation of $1.69^{\circ} \pm 1.02^{\circ}$ and a labiopalatal angulation of $1.56^{\circ} \pm 0.92^{\circ}$. However, in their systematic review, Tahmaseb et al. [8] reported that the mean errors of implant placement were approximately 1.2 and $1.4 \mathrm{~mm}$ at the coronal and apical points, respectively, with a deviation of $3.5^{\circ}$. The reported accuracy of CAI varied among multiple studies [13].

Various factors can affect the accuracy of implant placement including CBCT data acquisition, intraoral condition transfer (conventional impression or intraoral scan), surgical guided stent manufacturing, improper guided stent fixation and positioning, and the design of a surgical template. Surgical guided stent designs are mainly of two types: multiple [14] and single [15]. In multiple-type stents, the metal-guiding sleeve attached to the surgical stent and coordinating-drilling keys are inserted into the sleeve for guidance purposes during implant preparation. The tolerance of the drilling key to the sleeve and the drills to the drilling key cause deviations of the accuracy in multiple-type stents. Cassetta et al. [15] identified an intrinsic error between the master and inner tubes in single-type stereolithographic-surgical stents. The present study examined a new and modified singletype surgical stent with individual single zirconia sleeves that were incorporated into the surgical stent to fit individual drills by using CAD software.

Accuracy is substantially affected by the tolerance of the gap-drill distance of the sleeve [15], guide sleeve height, drilling distance, drilling key length [16], and surgical sites of the jaw [17]. Kholy et al. [16] demonstrated that reducing the drilling distance or increasing the sleeve height $(3 \mathrm{~mm})$ could significantly increase the accuracy of static CAI surgeries. Furthermore, Schneider et al. [18] reported that a greater sleeve height reduced the lateral movement of implant placement and improved overall accuracy. Most relevant studies have reported that imposing more limitations on the guided stent improved the accuracy of implant placement.

Surgeries performed using a CAI template are more accurate than those performed using conventional surgical guides [19]. However, drill sleeve tolerance may directly affect deviation errors during surgery $[15,20]$. The present study investigated the accuracy of varying drill sleeve distances in multiple positions and the wear conditions between the drill and sleeves. This study hypothesized that the application of small drill-sleeve distance would increase the accuracy of implant installation and induce more wear during surgery.

\section{Materials and Methods}

\subsection{Model Preparation}

Fifteen sets of upper and lower partially edentulous epoxy tooling board models, which were milled in the same open CNC (computer numerical control) system milling center (Ardenta CNC mill, DT100-4A, Tainan, Taiwan) with new tungsten-carbide burs, were placed in a Nissin Simple Manikin II (Nissin, Japan) and set on a dental chair to simulate clinical conditions. The missing teeth on these models were the upper right first molars, upper left first molars, lower right first molars, and lower left first molars. An experienced right-handed surgeon prepared implants for the present study by following implant surgical protocol (Figure 1).

Digital wax-ups of the missing teeth and ideal implant installation planning were performed using CAD software (exocad DentalCAD; exocad $\mathrm{GmbH}$ ). A total of 30 singletype CAD/CAM-guided stents ( $3 \mathrm{~mm}$ thickness) were fabricated using clear PMMA materials and zirconia sleeves ( $4 \mathrm{~mm}$ height) for missing tooth areas. Three internal tubes with different drill sleeve distances $(3.61,3.62$, and $3.63 \mathrm{~mm}$ ) (Figure 2) were designed to fit their respective drills (3.6 mm diameter, Axiom REG, Anthogyr, Sallanches, France) at four 
partially edentulous areas. In total, 60 new drills with 60 guide sets were prepared in the present study.

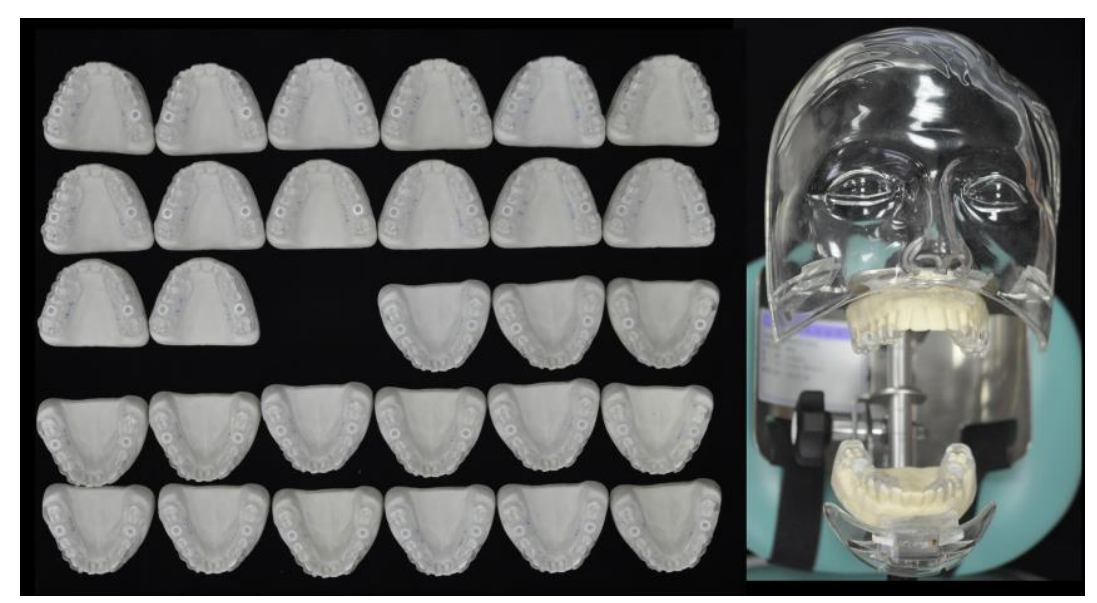

Figure 1. Simulated clinical position and the guided stents on epoxy tooling board model.

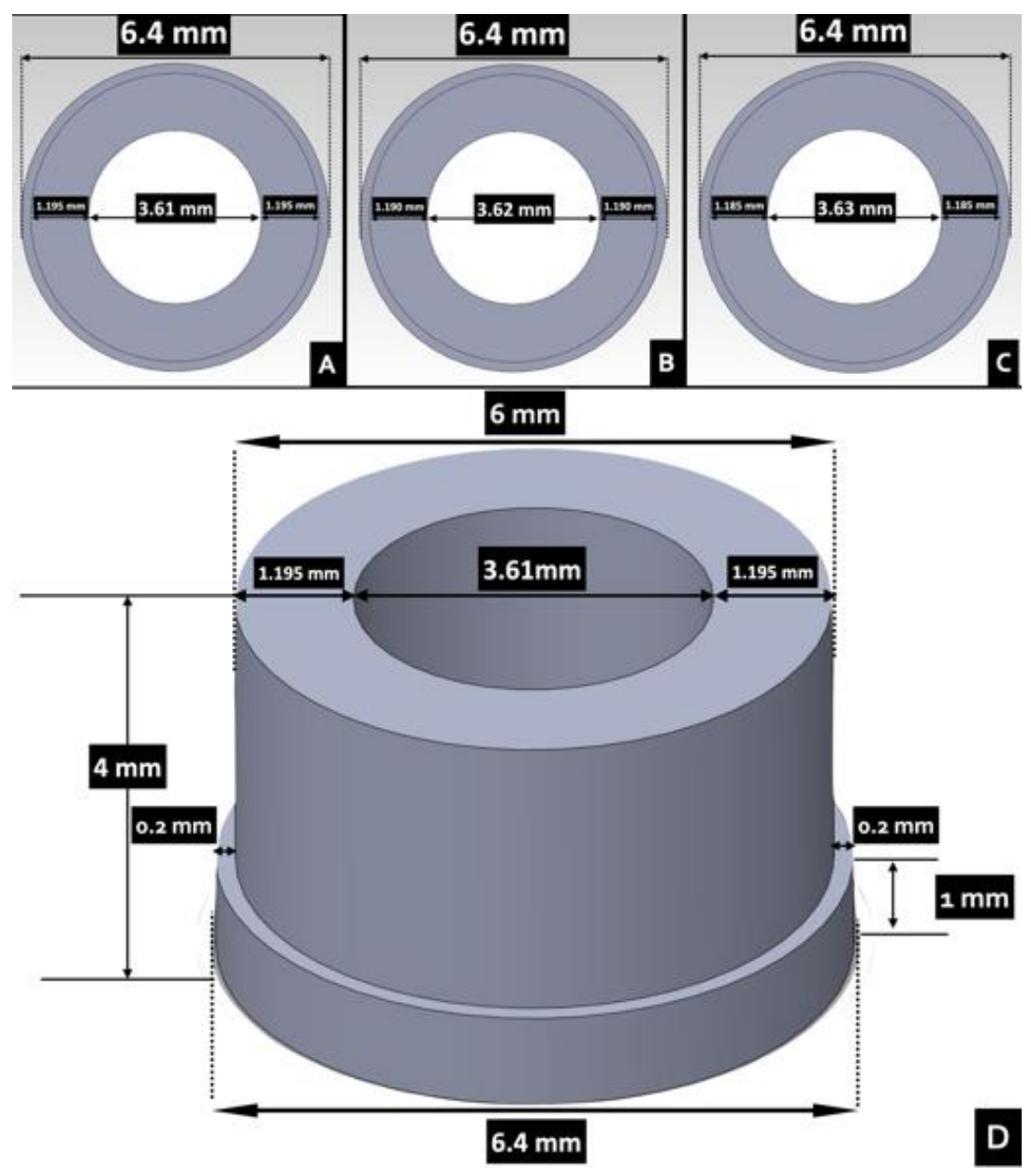

Figure 2. Design of zirconia sleeve: (A) $3.61 \mathrm{~mm}$ inner tube distance, $1.195 \mathrm{~mm}$ sleeve wall thickness; (B) $3.62 \mathrm{~mm}$ inner tube distance, $1.190 \mathrm{~mm}$ sleeve wall thickness; (C) $3.63 \mathrm{~mm}$ inner tube distance, $1.185 \mathrm{~mm}$ sleeve wall thickness; (D) $4 \mathrm{~mm}$ sleeve height and external diameter of tube is $1 \mathrm{~mm}$ height, $6.4 \mathrm{~mm}$ sleeve width on occlusal side, $6 \mathrm{~mm}$ sleeve width on tissue side. 


\subsection{Implant Placement}

Sixty new drills (3.6 $\mathrm{mm}$ in diameter and $10 \mathrm{~mm}$ in length) were sequentially drilled into missing tooth areas in the following order: right maxilla, left maxilla, left mandible, and right mandibular sites. After the preparation was completed, all drills were evaluated using a 3D optical profilometer (Bruker, German; Figures 3 and 4) to examine wear conditions, and internal tubes were observed using an EM-2.5D semi-automatic series specification (MIMN TAIY, Taiwan; Figure 5). The maximum height (Sz) is a roughness parameter defined as the sum of the largest peak-height and valley-depth values (ISO 25178). The time of drilling was calculated, and images were compared to evaluate the effect of the drill sleeve distance. CBCT was performed for 60 preparation modes, and their images were superimposed with virtually planned positions to compare horizontal, vertical, and angle deviations (Figure 6).

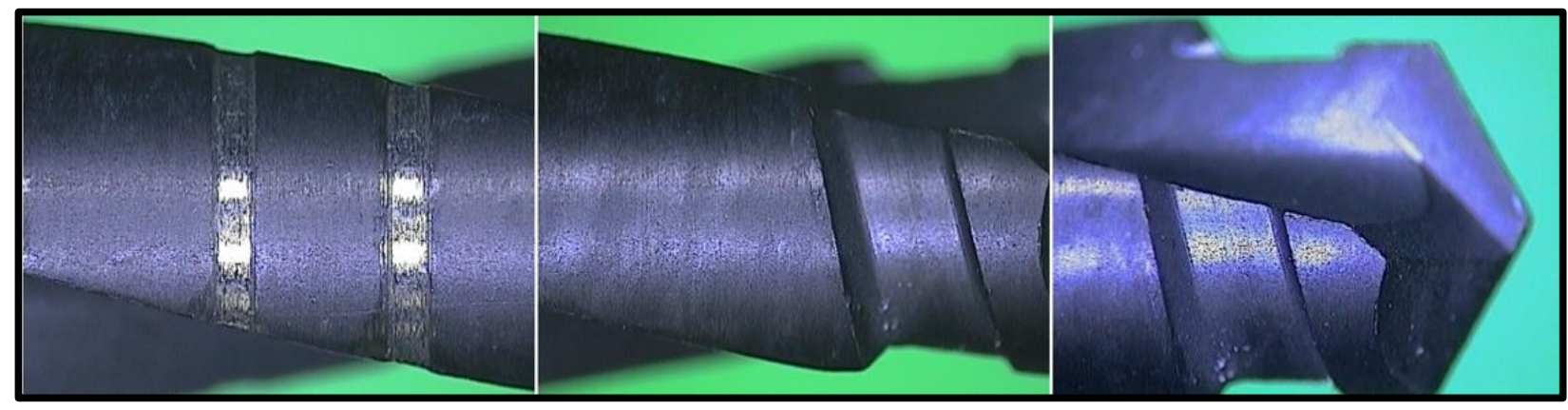

Figure 3. The whole drill was surveyed using 3D optical profilometer, and the wear roughness of drills was investigated on the widest part of the drill.
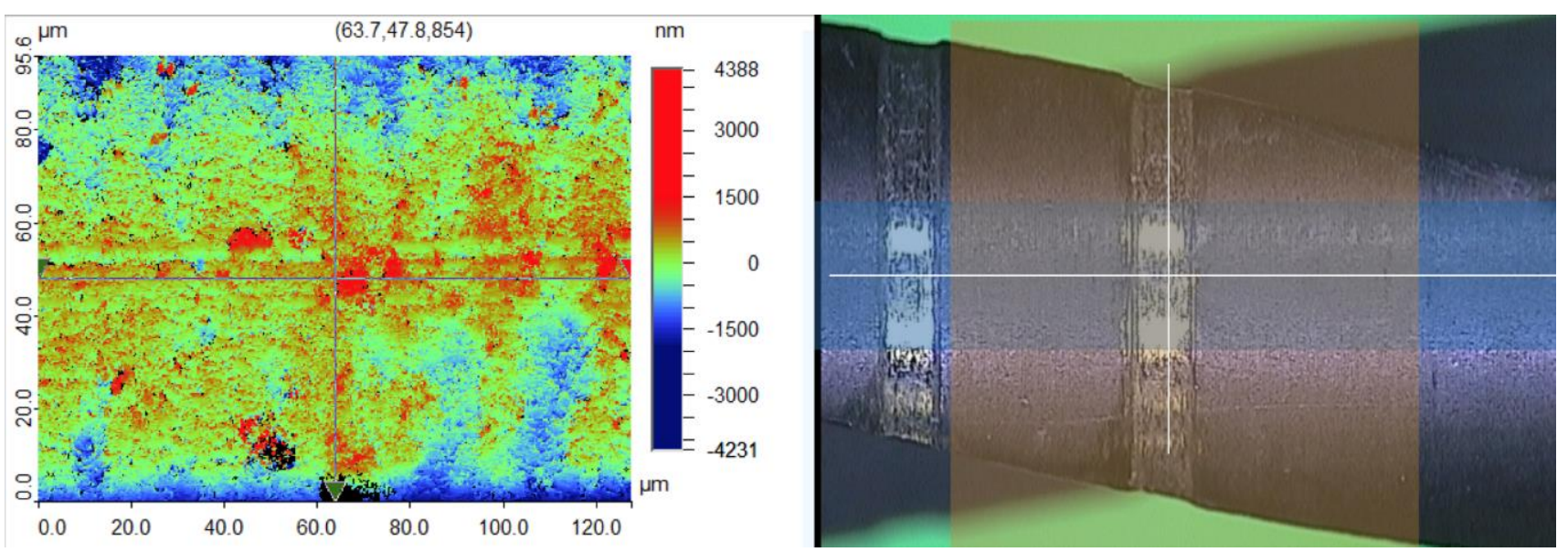

Figure 4. Evaluation of the wear roughness of drills by determining the maximum height (Sz).

\subsection{Statistical Analysis}

All statistical analyses were conducted using IBM SPSS (SPSS Statistics for Windows, v20; IBM, Armonk, NY, USA). Collected data were exported to an Excel sheet and analyzed using the Kruskal-Wallis equality-of-population rank test. A $p$-value of $<0.05$ was considered to be statistically significant. 


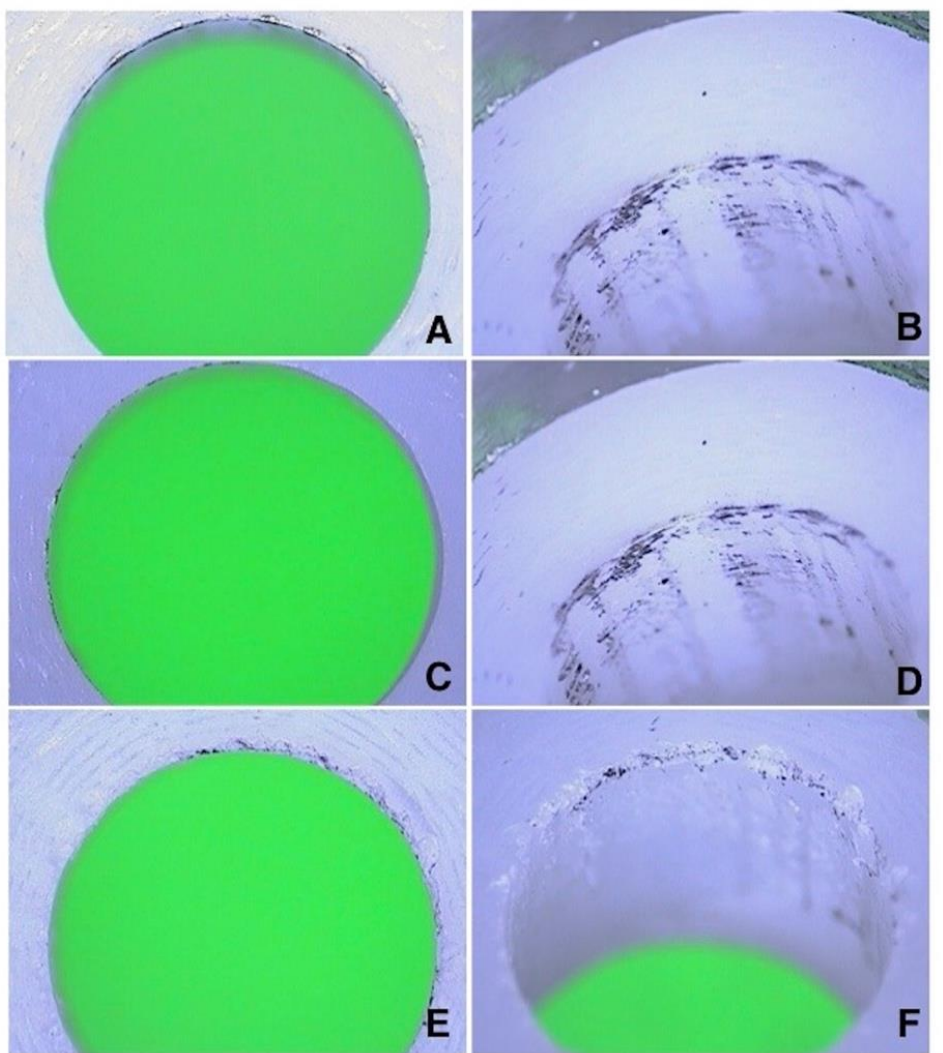

Figure 5. Green background and different wear of zirconia sleeves for the three drill-sleeve distances of (A,B) $0.01 \mathrm{~mm},(\mathbf{C}, \mathbf{D}) 0.02 \mathrm{~mm}$, and (E,F) $0.03 \mathrm{~mm}$ was shown via using an EM-2.5D semi-automatic series specification. The $0.03 \mathrm{~mm}$ showed more wear among three distances.

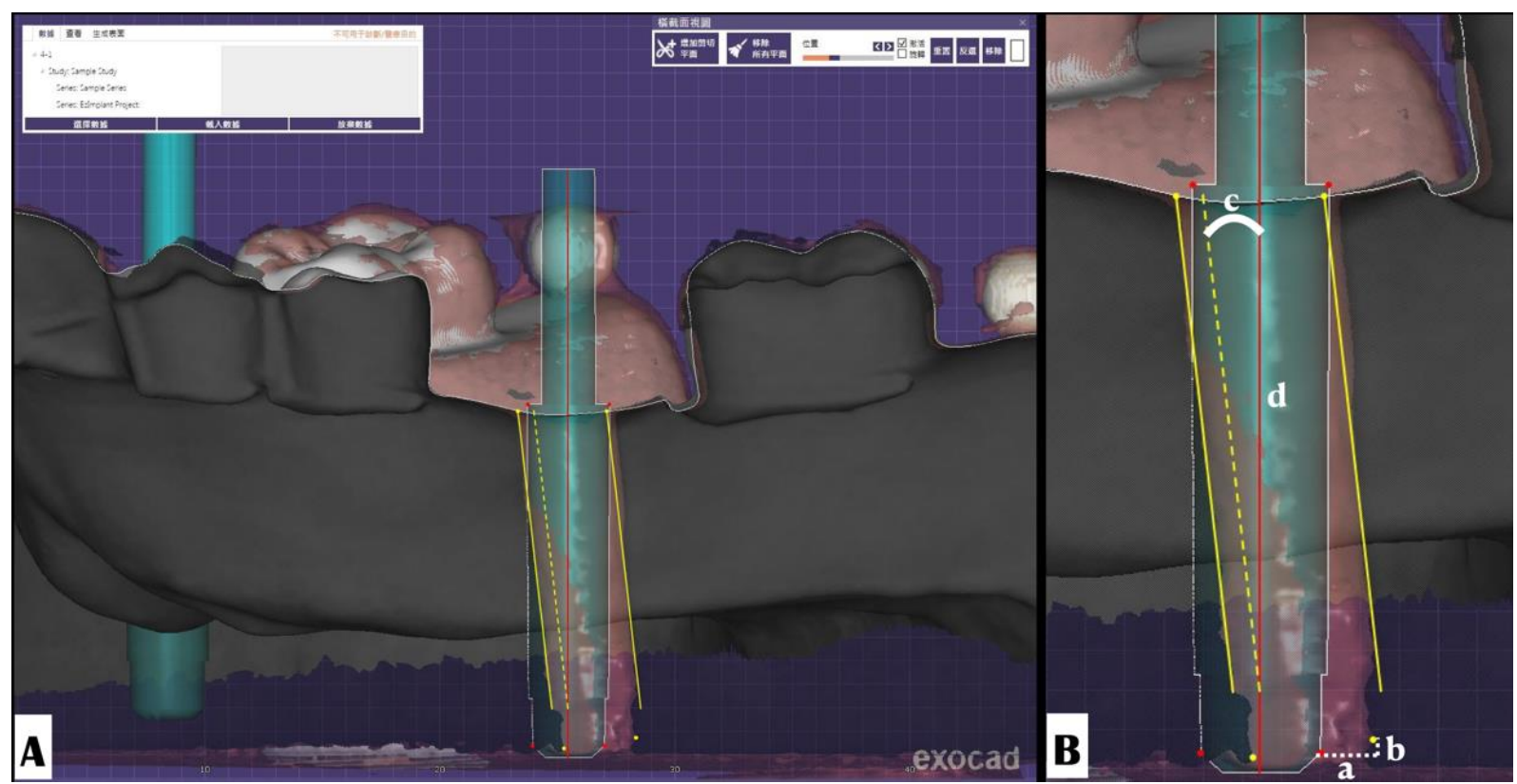

Figure 6. (A) Superimposition of the virtual plan and postsurgical position; measurement of points and angle deviations are based on the reference line. (B) a: horizontal deviation measurement between red dots (reference point) and yellow dots (postsurgical point); b: vertical deviation measurement; c: angulation deviation measurement; $d$ : reference line (red line): the central axis of ideal implant position. 


\section{Results}

Table 1 lists the deviations of the implant installation with respect to multiple tooth positions and varying drill sleeve distances. The results of 60 analyzed cases revealed horizontal, vertical, and angular deviations. The maximum horizontal deviations did not significantly differ among the three drill sleeve distances $(0.01 \mathrm{~mm}, 0.21 \pm 0.17 \mathrm{~mm}$; $0.02 \mathrm{~mm}, 0.21 \pm 0.18 \mathrm{~mm}$; and $0.03 \mathrm{~mm}, 0.26 \pm 0.19 \mathrm{~mm} ; p=0.603)$. The maximum vertical deviations did not significantly differ among the three gap distances $(0.01 \mathrm{~mm}$, $0.59 \pm 0.38 \mathrm{~mm} ; 0.02 \mathrm{~mm}, 0.72 \pm 0.36 \mathrm{~mm}$; and $0.03 \mathrm{~mm}, 0.86 \pm 0.51 \mathrm{~mm} ; p=0.145)$. The angular deviations did not significantly differ among the three gap distances $(0.01 \mathrm{~mm}$, $2.1^{\circ} \pm 2.15^{\circ} ; 0.02 \mathrm{~mm}, 3.17^{\circ} \pm 2.45^{\circ}$; and $\left.0.03 \mathrm{~mm}, 3.92^{\circ} \pm 1.87^{\circ} ; p=0.046\right)$. A wider gap distance was associated with an increased tendency of the occurrence of accuracy errors. The upper-right first molar site exhibited the highest horizontal deviation among the four quarter sites $(p<0.001)$. The lower left first molar site exhibited the highest vertical value $(p=0.001)$ and angular deviation $(p<0.001)$.

Table 1. Deviations of implant installation for multiple drill sleeve distances and positions.

\begin{tabular}{|c|c|c|c|c|c|c|}
\hline \multirow[b]{2}{*}{ Varies } & \multicolumn{2}{|c|}{$\begin{array}{l}\text { Maximum Horizontal Deviation } \\
(\mathrm{mm})\end{array}$} & \multicolumn{2}{|c|}{$\begin{array}{c}\text { Maximum Vertical Deviation } \\
\text { (mm) }\end{array}$} & \multicolumn{2}{|c|}{ Angulation ( ${ }^{\circ}$ ) } \\
\hline & $\mathbf{M} \pm \mathbf{S D}$ & $p$ & $\mathbf{M} \pm \mathbf{S D}$ & $p$ & $\mathbf{M} \pm \mathbf{S D}$ & $p$ \\
\hline Position & & $<0.001$ * & & 0.001 * & & $<0.001$ * \\
\hline $16(n=15)$ & $0.48 \pm 0.12^{a}$ & & $0.5 \pm 0.32^{c}$ & & $3.33 \pm 2.28^{f}$ & \\
\hline $26(n=15)$ & $0.14 \pm 0.07^{b}$ & & $0.77 \pm 0.51$ ce & & $1.98 \pm 1.52^{\mathrm{fh}}$ & \\
\hline $36(n=15)$ & $0.12 \pm 0.08^{b}$ & & $1.08 \pm 0.35^{\mathrm{de}}$ & & $5.61 \pm 1.21 \mathrm{~g}$ & \\
\hline $46(n=15)$ & $0.13 \pm 0.07^{b}$ & & $0.6 \pm 0.24^{c}$ & & $1.44 \pm 1.38^{h}$ & \\
\hline Distance & & 0.603 & & 0.145 & & $0.046^{*}$ \\
\hline $0.01(n=20)$ & $0.21 \pm 0.17$ & & $0.59 \pm 0.38$ & & $2.1 \pm 2.15^{\mathrm{i}}$ & \\
\hline $0.02(n=20)$ & $0.21 \pm 0.18$ & & $0.72 \pm 0.36$ & & $3.17 \pm 2.45^{\mathrm{ij}}$ & \\
\hline $0.03(n=20)$ & $0.26 \pm 0.19$ & & $0.86 \pm 0.51$ & & $3.92 \pm 1.87^{\mathrm{j}}$ & \\
\hline
\end{tabular}

Superscript letters in the columns indicate statistical significance among groups $\left({ }^{*} p<0.05\right.$; Kruskal-Wallis equality-of-population rank test, posthoc Dunn's multiple comparison test).

Table 2 presents the operation time and wear results for multiple drill sleeve distances and positions. Drilling time did not differ significantly among the three drill sleeve distances $(p=0.970)$ and anatomical sites $(p=0.627)$. Drill wear did not differ significantly among the three drill sleeve distances $(p=0.677)$ and anatomical sites $(p=0.791)$. However, compared with other positions, the positions of 16 and 46 exhibited higher mean values for the maximum height $(8.34$ and $8.88 \mu \mathrm{m}$, respectively) related to drill roughness.

Table 2. Operation time and implant surface wear for multiple drill sleeve distances and positions.

\begin{tabular}{ccccc}
\hline & Time (s) & & Sz $(\mu \mathbf{m})$ & \\
\hline Varies & $\mathbf{M} \pm \mathbf{S D}$ & $\boldsymbol{p}$ & $\mathbf{M} \pm \mathbf{S D}$ & $\boldsymbol{p}$ \\
\hline Position & & 0.627 & & 0.791 \\
$16(n=15)$ & $20.67 \pm 2.84$ & & $8.34 \pm 1.64$ & \\
$26(n=15)$ & $20.86 \pm 2.13$ & & $8.17 \pm 1.58$ & \\
$36(n=15)$ & $20.17 \pm 3.11$ & & $8.81 \pm 1.40$ & \\
$46(n=15)$ & $20.29 \pm 2.59$ & & & \\
Distance & & 0.970 & & \\
$0.01(n=20)$ & $20.46 \pm 2.66$ & & $8.04 \pm 1.78$ & \\
$0.02(n=20)$ & $20.52 \pm 2.63$ & & $8.17 \pm 1.46$ & \\
$0.03(n=20)$ & $20.50 \pm 2.75$ & & $8.70 \pm 2.29$ & \\
\hline
\end{tabular}

Kruskal-Wallis equality-of-population rank test; $p<0.05$ indicates statistical significance. $\mathrm{Sz}$ is the sum of the maximum peak height and maximum valley depth. 


\section{Discussion}

The present study examined single-type surgical stents with varying CAD/CAM zirconia drill sleeve distances to determine the accuracy and wear conditions in simulated clinical positions. Tahmaseb et al. [8] conducted a systematic review and reported a mean deviation of 0.9 to $1.2 \mathrm{~mm}$ and $3.3^{\circ}$ angular deviation for partially edentulous cases. Moreover, the results of accuracy were affected from various tooth positions; the upper right first molar exhibited the maximum horizontal deviation, and the lower left first molar exhibited the maximum vertical and angular deviations.

Drill sleeve distance did not affect horizontal and vertical deviations; however, the maximum angular deviation was observed after the application of a drill sleeve distance of $0.03 \mathrm{~mm}$. Tang et al. [7] reported that the various quadrants of a surgical site produced varying implant deviations in a free-hand placement protocol; their results indicated that the maxilla site (first and second quadrants) was associated with a significant buccolingual angulation and apical point deviation, and the third quadrant was associated with a significant mesiodistal angulation deviation. A systematic review [21] reported a greater angular deviation of implant placement performed using a guided stent for the maxilla than the mandible. This finding can be attributable to the inadequate stability of the guided stent for placement in the fully edentulous maxilla, thus resulting in accuracy errors.

To the best of our knowledge, no study has examined single tooth-gap implantation by using a guided stent. The findings of our in vitro study partially correspond to those of previous studies. Our results indicate that the maximum horizontal deviation of the upper right first molar can be attributable to the impaction of the surgical position by the right-handed surgeon. Kapoor et al. [22] reported that left-handed dental students found the maxilla to be more difficult to operate on than the mandible, with Quarter I being the most challenging to work on. The lower left first molar exhibited a significant difference in vertical and mesiodistal angulation deviations in our study; this could be related to the surgical habits of the right-handed surgeon who worked visually from the anterior-mesial side to the posterior-distal side, resulting in drilling deviations despite the restriction of the pathway by the static-guided stent.

Horwitz et al. [23] demonstrated that the multiple-use sleeve causes sleeve-wall attrition, thus increasing implant deviation. Cassetta et al. [24] indicated that a higher tolerance to system components is associated with the presence of larger intrinsic errors in a system. The present study demonstrated that a distance range of 0.01 to $0.03 \mathrm{~mm}$ for drill sleeves did not affect horizontal and vertical deviations. A narrower sleeve (i.e., 0.01 $\mathrm{mm}$ ) has the advantage of providing the minimal angular deviation of im-plantation; the disadvantage of a narrower sleeve is that it may produce overheating during drill-sleeve contact. However, more sleeve wear (Figure 5) was found in a bigger drill-sleeve distance (i.e., $0.03 \mathrm{~mm}$ ); this could be relevant to the greater tolerance for deviated drill side cutting the sleeve.

Drill sleeve contact during implant surgery may increase the wear debris, causing unfavorable results such as poor wound healing or osteointegration failure [25]. Koop et al. [26] advised clinicians to move the drill in and out of the guide multiple times to identify the smoothest drill position and allow sufficient irrigation. Shneider et al. [18] demonstrated that the tolerance of surgical instruments and lateral drill movements can be significantly reduced with the application of $3 \mathrm{D}$ printing to achieve a decreased sleeve diameter.

Ozan et al. [27] recommended using zirconia as the sleeve material because of better biocompatibility and less sleeve wear. The presented study examined single-type stents with a zirconia sleeve incorporated in one stent. Zirconia is a manufacturing-friendly and easily accessible material in clinical dentistry. CNC milling or 3D printing can be utilized to produce surgical templates with zirconia sleeves that are cost-efficient and can be easily modified for various surgical instruments. The limitations of the present study are as follows. The effects of the clinical saliva and tongue were not simulated and examined. Furthermore, no assistant was assigned to double check the positions. 
The results would have benefited from larger sample sizes for all edentulous areas. The authors will compare between single- and multiple-type surgical stents in a future clinical study.

\section{Conclusions}

The results indicated that adjusting the drill sleeve distance $(0.01-0.03 \mathrm{~mm}) \mathrm{did}$ not significantly affect horizontal and vertical deviations $(p>0.05)$. The drill wear did not differ significantly among three drill sleeve distances $(p=0.627)$; however, the maximum angular deviation $\left(3.92^{\circ} \pm 1.87^{\circ}\right)$ was observed after the application of a drill sleeve distance of $0.03 \mathrm{~mm}$. In practice, a single-type CAD/CAM zirconia-guided stent was recommended. The optimal drill sleeve distance for guided stents should be $0.01 \mathrm{~mm}$.

Author Contributions: Conceptualization, T.-H.L. and Y.-F.C.; methodology, C.-Y.P.; validation, Y.-F.C., C.-Y.P., and T.-H.L.; formal analysis, T.-H.L. and Y.-C.C.; software, Y.-C.C.; supervision, T.-H.L. and J.-K.D.; writing—original draft, Y.-F.C.; writing-review and editing, T.-H.L., Y.-F.C., C.-Y.P., Y.-C.C., and J.-K.D. All authors have read and agreed to the published version of the manuscript.

Funding: This research was partially funded by Ministry of Science and Technology of Taiwan (MOST 105-2622-E-037-004-CC3 \& MOST 110-2314-B-037-059) and KMUH Research Project (KMUHSA10909).

Institutional Review Board Statement: Not applicable.

Informed Consent Statement: Not applicable.

Acknowledgments: The authors thank Lin, Hui-Chin, a dental laboratory technician in Fu Jia dental laboratory Office, for his helpful laboratory support. The authors also thanks E.S.T. BIOTECH INC. for the Anthogyr Implant fixtures support.

Conflicts of Interest: The authors declare no conflict of interest.

\section{References}

1. Cassetta, M.; Altieri, F.; Giansanti, M.; Bellardini, M.; Brandetti, G.; Piccoli, L. Is there a learning curve in static computer-assisted implant surgery? A prospective clinical study. Int. J. Oral Maxillofac. Surg. 2020, 49, 1335-1342. [CrossRef]

2. Marchack, C.B.; Moy, P.K. Computed tomography-based, template-guided implant placement and immediate loading: An 8-year clinical report. J. Prosthet. Dent. 2014, 112, 1319-1323. [CrossRef]

3. Deeb, G.R.; Allen, R.K.; Hall, V.P.; Whitley, D., III; Laskin, D.M.; Bencharit, S. How accurate are implant surgical guides produced with desktop stereolithographic 3-dimentional printers? J. Oral Maxillofac. Surg. 2017, 75, 2559.e1-2559.e8. [CrossRef]

4. Seo, C.; Juodzbalys, G. Accuracy of guided surgery via stereolithographic mucosa-supported surgical guide in implant surgery for edentulous patient: A systematic review. J. Oral Maxillofac. Res. 2018, 9, e1. [CrossRef]

5. Colombo, M.; Mangano, C.; Mijiritsky, E.; Krebs, M.; Hauschild, U.; Fortin, T. Clinical applications and effectiveness of guided implant surgery: A critical review based on randomized controlled trials. BMC Oral Health 2017, 17, 1-9. [CrossRef]

6. Sun, T.-M.; Lee, H.-E.; Lan, T.-H. Comparing accuracy of implant installation with a Navigation System (NS), a Laboratory Guide (LG), NS with LG, and Freehand Drilling. Int. J. Environ. Res. Public Health 2020, 17, 2107. [CrossRef]

7. Tang, T.; Huang, Z.; Liao, L.; Gu, X.; Zhang, J.; Zhang, X. Factors that influence direction deviation in freehand implant placement. J. Prosthodont. 2019, 28, 511-518. [CrossRef]

8. Tahmaseb, A.; Wu, V.; Wismeijer, D.; Coucke, W.; Evans, C. The accuracy of static computer-aided implant surgery: A systematic review and meta-analysis. Clin. Oral Implants Res. 2018, 29, 416-435. [CrossRef]

9. Chen, Y.; Zhang, X.; Wang, M.; Jiang, Q.; Mo, A. Accuracy of full-guided and half-guided surgical templates in anterior immediate and delayed implantation: A retrospective study. Materials 2021, 14, 26. [CrossRef]

10. Azari, A.; Nikzad, S. Computer-assisted implantology: Historical background and potential outcomes-A review. Int. J. Med. Robot. 2008, 4, 95-104. [CrossRef]

11. D'haese, J.; Ackhurst, J.; Wismeijer, D.; De Bruyn, H.; Tahmaseb, A. Current state of the art of computer-guided implant surgery. Periodontology 2000 2017, 73, 121-133. [CrossRef]

12. Yeung, M.; Abdulmajeed, A.; Carrico, C.K.; Deeb, G.R.; Bencharit, S. Accuracy and precision of 3D-printed implant surgical guides with different implant systems: An in vitro study. J. Prosthet Dent. 2020, 123, 821-828. [CrossRef]

13. Tahmaseb, A.; Wismeijer, D.; Coucke, W.; Derksen, W. Computer technology applications in surgical implant dentistry: A systematic review. Int. J. Oral Maxillofac. Implants 2014, 29, 25-42. [CrossRef] 
14. Mandelaris, G.A.; Rosenfeld, A.L.; King, S.D.; Nevins, M.L. Computer-guided implant dentistry for precise implant placement: Combining specialized stereolithographically generated drilling guides and surgical implant instrumentation. Int. J. Periodontics Restor. Dent. 2010, 30, 275-281.

15. Cassetta, M.; Di Mambro, A.; Giansanti, M.; Stefanelli, L.; Cavallini, C. The intrinsic error of a stereolithographic surgical template in implant guided surgery. Int. J. Oral Maxillofac. Surg. 2013, 42, 264-275. [CrossRef]

16. El Kholy, K.; Janner, S.F.M.; Schimmel, M.; Buser, D. The influence of guided sleeve height, drilling distance, and drilling key length on the accuracy of static Computer-Assisted Implant Surgery. Clin. Implant Dent. Relat Res. 2019, 21, 101-107. [CrossRef]

17. Noharet, R.; Pettersson, A.; Bourgeois, D. Accuracy of implant placement in the posterior maxilla as related to 2 types of surgical guides: A pilot study in the human cadaver. J. Prosthet. Dent. 2014, 112, 526-532. [CrossRef]

18. Schneider, D.; Schober, F.; Grohmann, P.; Hammerle, C.H.; Jung, R.E. In-vitro evaluation of the tolerance of surgical instruments in templates for computer-assisted guided implantology produced by 3-D printing. Clin. Oral Implants Res. 2015, 26, 320-325. [CrossRef]

19. Vercruyssen, M.; Jacobs, R.; Van Assche, N.; van Steenberghe, D. The use of CT scan based planning for oral rehabilitation by means of implants and its transfer to the surgical field: A critical review on accuracy. J. Oral Rehabil. 2008, 35, 454-474. [CrossRef]

20. Schneider, D.; Marquardt, P.; Zwahlen, M.; Jung, R.E. A systematic review on the accuracy and the clinical outcome of computerguided template-based implant dentistry. Clin. Oral Implant. Res. 2009, 20, 73-86. [CrossRef]

21. Zhou, W.; Liu, Z.; Song, L.; Kuo, C.L.; Shafer, D.M. Clinical factors affecting the accuracy of guided implant surgery-a systematic review and meta-analysis. J. Evid. Based Dent. Pract. 2018, 1, 28-40. [CrossRef] [PubMed]

22. Kapoor, S.; Puranik, M.P.; Uma, S.R. Practice perspectives of left-handed clinical dental students in India. J. Clin. Diagn Res. 2016, 10, 79-83. [CrossRef] [PubMed]

23. Horwitz, J.; Zuabi, O.; Machtei, E.E. Accuracy of a computerized tomography-guided template-assisted implant placement system: An in vitro study. Clin. Oral Implant. Res. 2009, 20, 1156-1162. [CrossRef] [PubMed]

24. Cassetta, M.; Di Mambro, A.; Di Giorgio, G.; Stefanelli, L.V.; Barbato, E. The influence of the tolerance between mechanical components on the accuracy of implants inserted with a stereolithographic surgical guide: A retrospective clinical study. Clin. Implant. Dent. Relat Res. 2015, 17, 580-588. [CrossRef] [PubMed]

25. Wilson, T.G., Jr.; Valderrama, P.; Burbano, M.; Blansett, J.; Levine, R.; Kessler, H.; Rodrigues, D.C. Foreign bodies associated with peri-implantitis human biopsies. J. Periodontol. 2015, 1, 9-15. [CrossRef]

26. Koop, R.; Vercruyssen, M.; Vermeulen, K.; Quirynen, M. Tolerance within the sleeve inserts of different surgical guides for guided implant surgery. Clin. Oral Implants Res. 2013, 24, 630-634. [CrossRef]

27. Ozan, O.; Şeker, E.; Çakmak, G.; Guo, X.; Yilmaz, B. Effect of guide sleeve material, region, diameter, and number of times drills were used on the material loss from sleeves and drills used for surgical guides: An in vitro study. J. Prosthet. Dent. 2021. [CrossRef] 